\title{
Performance measurements of the collective Thomson scattering receiver at ASDEX Upgrade
}

Furtula, Vedran; Leipold, Frank; Salewski, Mirko; Michelsen, Poul; Korsholm, Søren Bang; Meo, Fernando; Moseev, Dmitry; Nielsen, Stefan Kragh; Stejner Pedersen, Morten; Johansen, Tom Keinicke

Published in:

Journal of Instrumentation

Link to article, DOI:

10.1088/1748-0221/7/02/C02039

Publication date:

2012

Link back to DTU Orbit

Citation $(A P A)$ :

Furtula, V., Leipold, F., Salewski, M., Michelsen, P., Korsholm, S. B., Meo, F., Moseev, D., Nielsen, S. K., Stejner Pedersen, M., \& Johansen, T. K. (2012). Performance measurements of the collective Thomson scattering receiver at ASDEX Upgrade. Journal of Instrumentation, 7(02), C02039. https://doi.org/10.1088/17480221/7/02/C02039

\section{General rights}

Copyright and moral rights for the publications made accessible in the public portal are retained by the authors and/or other copyright owners and it is a condition of accessing publications that users recognise and abide by the legal requirements associated with these rights.

- Users may download and print one copy of any publication from the public portal for the purpose of private study or research.

- You may not further distribute the material or use it for any profit-making activity or commercial gain

- You may freely distribute the URL identifying the publication in the public portal 


\title{
Performance measurements of the collective Thomson scattering receiver at ASDEX Upgrade
}

\author{
V. Furtula, ${ }^{a, 1}$ F. Leipold, ${ }^{a}$ M. Salewski, ${ }^{a}$ P. K. Michelsen, ${ }^{a}$ S. B. Korsholm, ${ }^{a}$ F. Meo, ${ }^{a}$ \\ D. Moseev, ${ }^{a}$ S. K. Nielsen, ${ }^{a}$ M. Stejner ${ }^{a}$ and T. Johansen ${ }^{b}$ \\ ${ }^{a}$ Association Euratom - Ris $\phi$ National Laboratory for Sustainable Energy, \\ Technical University of Denmark, DK-4000 Roskilde, Denmark \\ ${ }^{b}$ DTU Elektro, \\ Technical University of Denmark, DK-2800 Lyngby, Denmark \\ E-mail: vefu@risoe.dtu.dk
}

\begin{abstract}
The fast-ion collective Thomson scattering (CTS) receiver at ASDEX Upgrade can detect spectral power densities of a few $\mathrm{eV}$ in the millimeter-wave range against the electron cyclotron emission (ECE) background on the order of $100 \mathrm{eV}$ under presence of gyrotron stray radiation that is several orders of magnitude stronger than the signal to be detected. The receiver heterodynes the frequencies of scattered radiation $(100-110 \mathrm{GHz})$ to intermediate frequencies (IF) (4.5-14.5 GHz). The IF signal is divided into 50 IF channels tightly spaced in frequency space which are terminated by square-law Schottky detector diodes. The performance of the entire receiver is determined by the main receiver components operating at mm-wave frequencies (notch-, bandpass- and lowpass filters, a voltage-controlled variable attenuator, and an isolator), a mixer, and the IF components (amplifiers, band-pass filters, and detector diodes). We discuss here the design of the entire receiver, focussing on its performance as a unit. The receiver has been disassembled, and the performance of its individual components has been characterized. Based on these individual component measurements we predict the spectral response of the receiver assembled as a unit. The measured spectral response of the assembled receiver is in reasonable agreement with this prediction.
\end{abstract}

KEYWORDS: mm-wave technology, receiver, collective Thomson scattering

\footnotetext{
${ }^{1}$ Corresponding author.
} 


\section{Contents}

1 Introduction 1

2 Schematic of the AUG CTS receiver 2

3 Characterization of the AUG CTS Receiver 3

4 Conclusions $\quad 6$

\section{Introduction}

We discuss here the performance of a receiver sensitive to frequencies in the mm-wavelength range (W - band) with the primary goal to detect electromagnetic radiation coming from the plasma that can reveal spatial and temporal information about populations of fast ions with collective Thomson scattering (CTS). The receiver is installed at ASDEX Upgrade (AUG) [1-3]. In fast-ion CTS measurements at AUG, a probing beam at $105 \mathrm{GHz}$ from a gyrotron is launched into the plasma and is scattered off collective fluctuations due to presence of fast ions. Information about the fastion velocity distribution can be inferred from the spectral power density of Doppler-broadened scattered radiation which is in the frequency range $100-110 \mathrm{GHz}$. The receiver uses a heterodyne detection scheme. Overviews of heterodyne methods used for plasma diagnostics are given in [4, 5].

CTS receivers can also be used for a variety of other measurements [6] and have been used to measure the ion temperature [7] and the fuel ion ratio [8, 9]. CTS receivers have been or are installed on several tokamaks and stellarators, for example at JET [10], W7-AS [7, 11], FTU [12, 13], TEXTOR [14-17], ASDEX Upgrade [1-3] or LHD [18]. Millimeter wave CTS is well-suited for the strongly radiative environments of ITER or future fusion reactors [19-21]. A CTS diagnostic has been enabled in ITER and will allow detection of the energy distribution of alpha particles in the burning plasma of ITER [22-24].

In this paper we will discus the performance of this technically challenging receiver installed on AUG. AUG is equipped with dual frequency $1 \mathrm{MW}$ gyrotrons which can be operated at $105 \mathrm{GHz}$ for CTS experiments [25, 26]. The radiation from the gyrotron is launched into the plasma. The scattered radiation is received by a steerable mirror and guided via a quasi-optical transmission line into a waveguide. Thereafter the radiation is fed via a quasi-optical transmission line and a circular horn antenna into the heterodyne microwave receiver.

A detailed schematic of the receiver is discussed in Section 2. In Section 3 we present measurements characterizing the performance of the entire receiver and compare these measurements with the expectation based on individual component measurements. We draw conclusions and discuss perspectives in Section 4. 


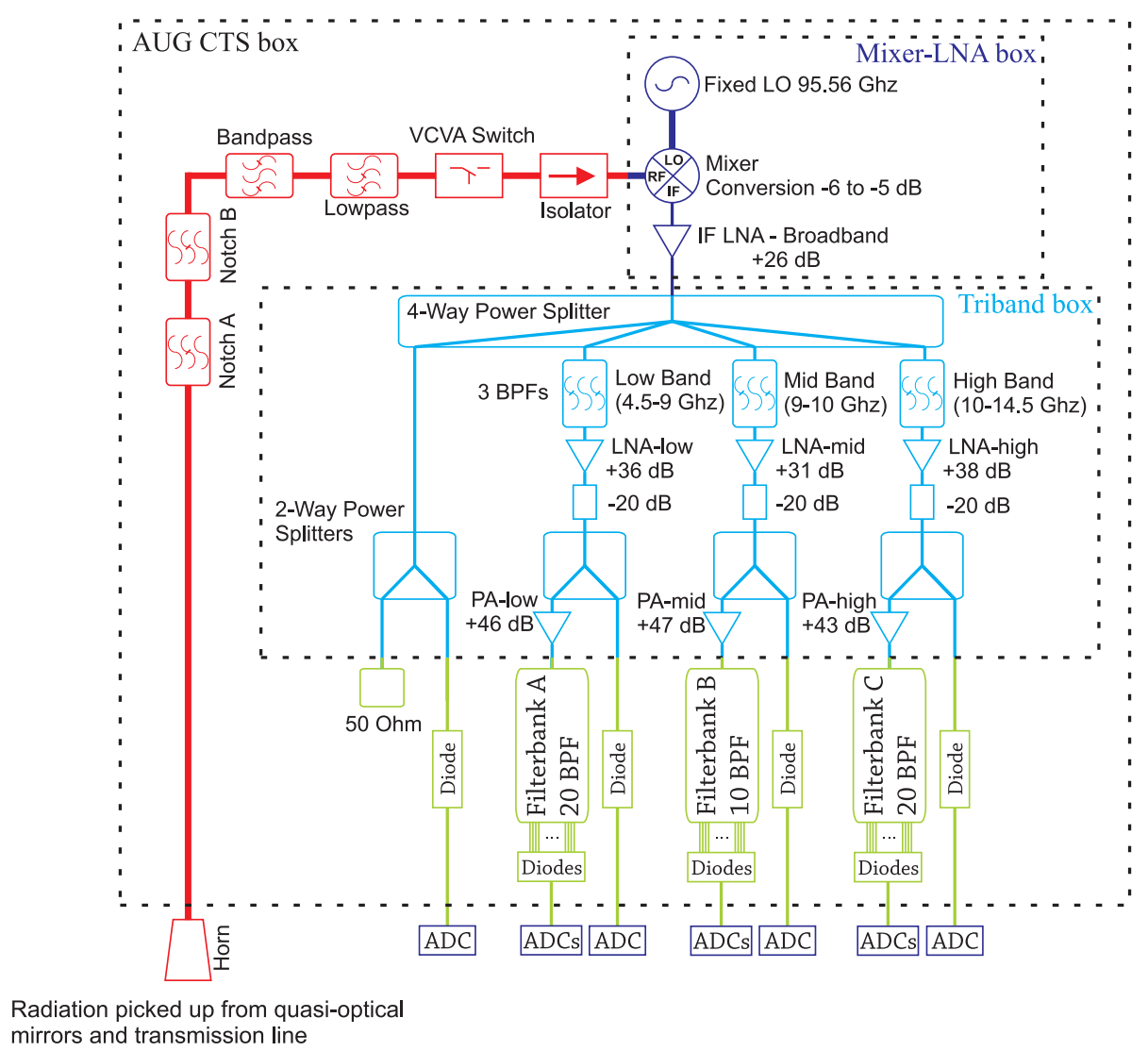

Figure 1. Schematic of AUG CTS receiver. The dashed lines represent shielding boxes in which the receiver components are installed. The RF line is shown in red; the mixer, the LO and the broadband LNA in the mixer-LNA box are shown in dark blue; the components in the triband box are shown in blue; and the filterbanks A, B and C and the detector diodes are shown in green.

\section{Schematic of the AUG CTS receiver}

A schematic of the AUG CTS receiver is shown in Fig. 1. All components are placed in an electrically shielded box. The radiation enters the horn antenna and passes through the W-band RF line (red in Fig. 1) consisting of the horn antenna, two notch filters, a bandpass filter, a lowpass filter, a voltage controlled variable attenuator (VCVA) and an isolator. Then the RF signal enters the mixing stage where the signal is heterodyned to intermediate frequencies (IF). The local oscillator (LO), the mixer and a wideband low-noise amplifier (LNA) are placed in a shielded compact copper box, called "Mixer-LNA box" (dark blue in Fig. 1). The LO source has an output power of approximately $13 \mathrm{dBm}$ which is several orders of magnitude higher than the predicted signal in the RF line during CTS experiments. The LO is placed in the mixer-LNA box to prevent cross-talk between the LO and RF lines. The IF signal at the LNA output is divided using a four-way power splitter and three bandpass filters into three frequency bands. These components are located in a shielded box that is called "Triband box" shown in blue (Fig. 1). The fourth branch in the triband box is used for auxiliary purposes only. After the triband box the IF signal is fed to the filterbanks A (4.5 - $9 \mathrm{GHz}), \mathrm{B}(9-10 \mathrm{GHz})$, and $\mathrm{C}(10-14.5 \mathrm{GHz})$ and divided into a total of 50 channels using 
power dividers and bandpass filters. Filterbanks $\mathrm{A}$ and $\mathrm{C}$ have 20 channels each whereas filterbank $\mathrm{B}$ has 10 channels. In each channel, the power after the bandpass filter is converted to a DC voltage using a square-law Schottky detector diode followed by a DC amplifier. The diode output voltage has negative polarity and is acquired using a 24-bit analog-to-digital converter (ADC).

\section{Characterization of the AUG CTS Receiver}

To measure the receiver performance, we use a single frequency source at the input of the RF line and measure the output voltage using 50 ADC channels. The setup of the source is composed of a signal generator and a frequency multiplier of sixth order $(\times 6)$ and two variable attenuators. The frequency multiplier is driven by the signal generator tunable in the range from 16 to $18.5 \mathrm{GHz}$ in $2.5 \mathrm{MHz}$ steps. The multiplier outputs are single frequency signals in the frequency range from 96 to $111 \mathrm{GHz}$ in $15 \mathrm{MHz}$ steps with a total power varying from 4 to $6 \mathrm{dBm}$. The output power from the frequency multiplier is too high for testing purposes, so we need to attenuate it with at least $50 \mathrm{~dB}$ before it enters the RF line. For this purpose we use two attenuators, the first one ${ }^{1}$ is tunable while the second ${ }^{2}$ is set to maximum attenuation. Individual calibrations are needed for both W-band attenuators since they are not necessarily linear for each frequency or setting option. The experiment setup is shown in Fig. 2. During the experiment we vary the narrow-band signal power by using the variable attenuator and the narrow-band signal frequency by tuning the input frequency of the $\times 6$ multiplier, and we record the readings on the ADCs for each channel.

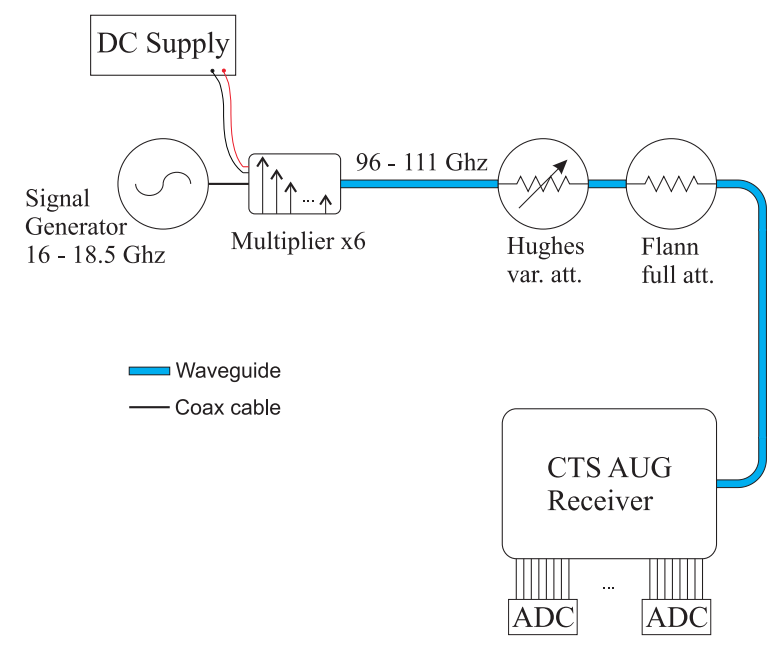

Figure 2. Measurement setup to determine the frequency response of the CTS AUG receiver. The 1618.5 GHz signal is converted to a $96-111 \mathrm{GHz}$ signal in the frequency multiplier and then passes a variable attenuator (Hughes) and a second attenuator (Flann) set to maximum attenuation before it enters the RF line of the CTS AUG receiver.

We show a global frequency response picture of the CTS receiver at one power level, here $-55 \mathrm{dBm}$, and measure the ADC voltages as function of frequency. Figures 3(a) and 3(b) present

\footnotetext{
${ }^{1}$ Hughes

${ }^{2}$ Flann
} 


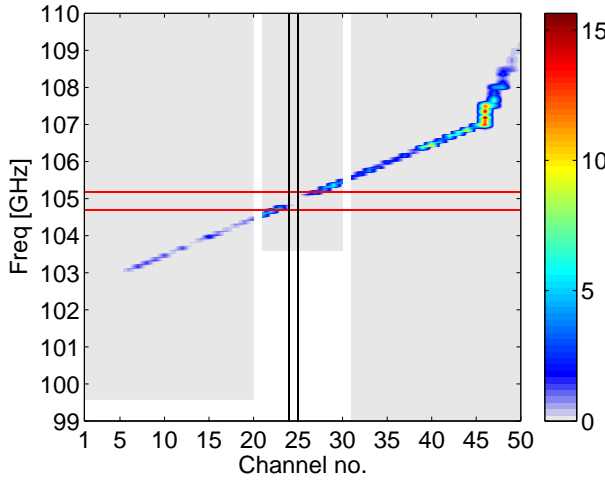

(a)

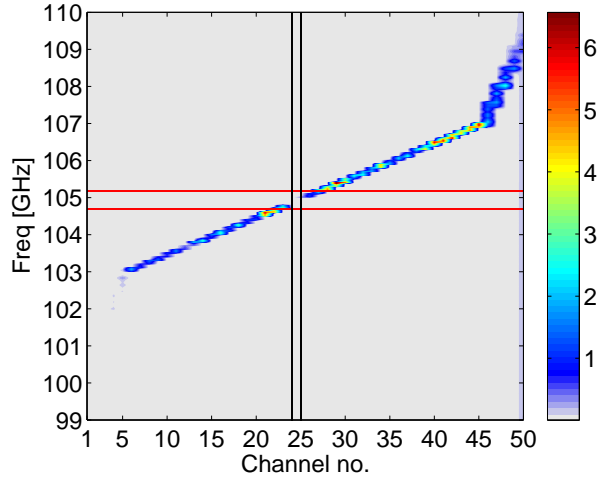

(b)

Figure 3. Voltage response of the receiver to multiplier narrow-band signal source with a fixed power of $-55 \mathrm{dBm}$. The channels containing the notch (24 and 25) are shown as vertical black lines: (a) Calculated voltage response [V] of the 50 frequency channels of the AUG CTS receiver to a narrowband signal that is swept in frequency. The calculation is based on individual component measurements; (b) Corresponding voltage response [V] measurement of the entire receiver assembled as a unit.

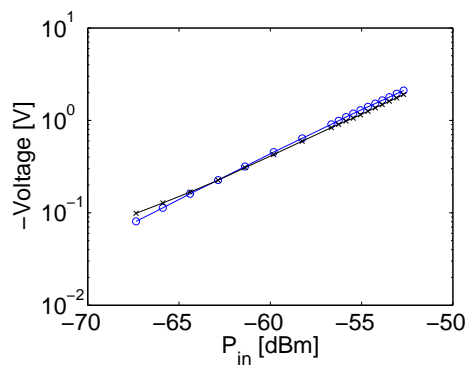

(a) Channel 9

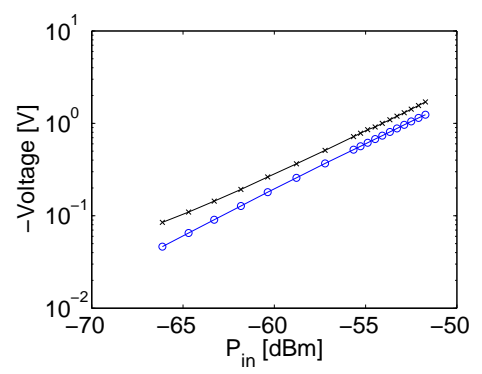

(d) Channel 17

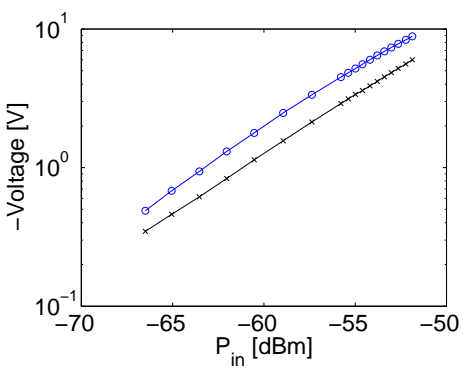

(b) Channel 22

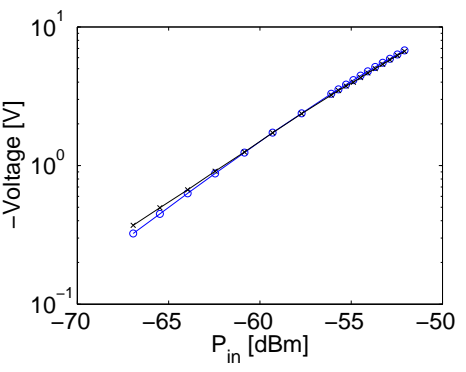

(e) Channel 28

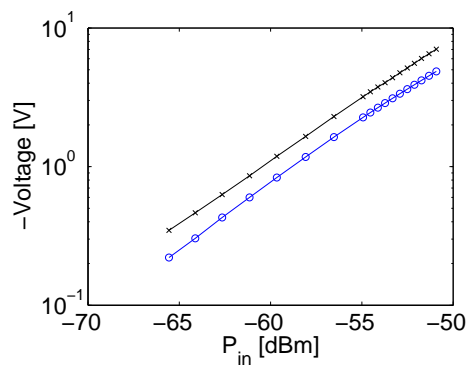

(c) Channel 34

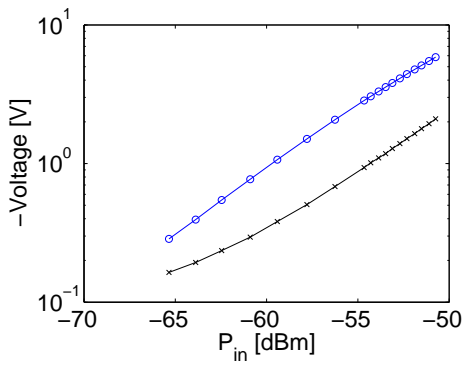

(f) Channel 47

Figure 4. Voltage-power characteristic of a few representative receiver channels with measurements in black and expectation based on individual component measurements in blue.

the predicted frequency response based on measurements of individual components and the corresponding measurement of the entire receiver as a unit, respectively. Each channel only has a voltage response at its design frequency, indicating that the filters have proper attenuation outside their design passband. Different shades of color along the CTS channels show that they do not have a flat frequency response. 
A second way to characterize the receiver is to increase the power and monitor the response of the 50 channels. Here we show data for a few representative channels: channels $(9,17),(22,28)$ and $(34,47)$ from filterbanks A, B and C, respectively. Fig. 4 shows the voltages at the ADCs as function of single frequency source power. The measurements are compared with the prediction based on the measurements of the individual components. We find reasonable agreement to within a factor of about 2.5. The slope of the curves in Fig. 4 is approximately unity in log-log scale. The linear growth of the voltage as function of power indicates that the diodes operate in the square-law region as expected.

To present a global picture of the differences between the measurements of the entire receiver and the prediction based on individual component measurements, we define the voltage ratio in $\mathrm{dB}$ as

$$
\Delta=10 \log \left\{\frac{V_{\text {measured }}}{V_{\text {predicted }}}\right\}
$$

where $V_{\text {measured }}$ is the voltage measured at the assembled receiver as one unit and $V_{\text {predicted }}$ is the voltage predicted due to the individual component measurements. These ratios of measured and predicted voltages in $\mathrm{dB}$ for our scan in frequency channels and input power are presented in Fig. 5. Note that the logarithm of the voltage ratio is negative for most channels and powers, which means that the measured voltage is lower than predicted. We also note that the voltage ratio $\Delta$ in each channel is approximately independent of the power but can vary from channel to channel. The simple method of adding S-parameters through the system, which we used for the prediction, can give us a qualitative and inexpensive picture of the receiver characteristics and is helpful when individual components of the system have to be replaced.

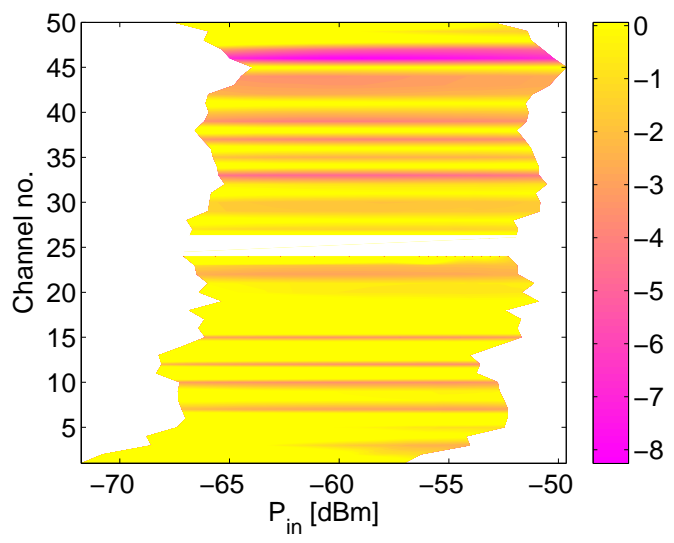

Figure 5. Voltage ratio $\Delta$ in $\mathrm{dB}$ measured at the 50 channels of the CTS AUG receiver for various power levels. Yellow colors indicates that the predicted voltage values are approximately similar to the measurements while pink indicates that the measured values are smaller compared with the expectation. 
The curves presented in figure 4 show voltage variation as function of input power for some chosen channels. The slope of these curves is called receiver sensitivity and has unit Volts per Watt. In figure 6 we show sensitivity for all 50 channels for the measured and expected cases. We observe that sensitivity in both cases varies with the same shape: the sensitivity in the low and mid banks is somewhat lower than the sensitivity in the high bank. High variation in sensitivity is caused by the variation in the gain across the channels, which implies that there is a risk that in some of the channels we might operate in both square-law and resistive diode regions causing the sensitivity to vary considerably as a function of power. This is a well known issue in total power radiometers such as the CTS receiver we present here.

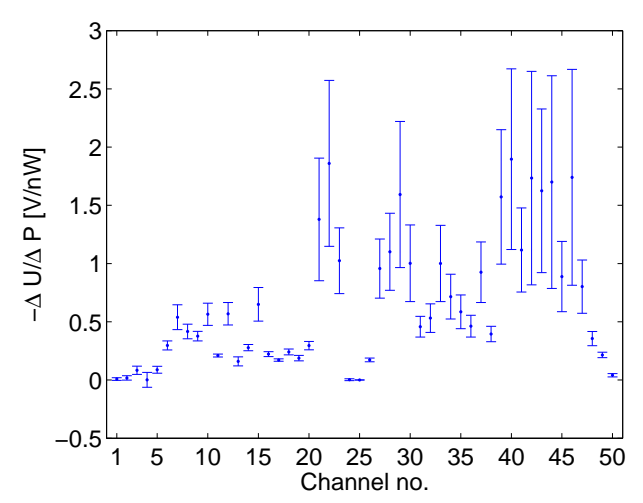

(a)

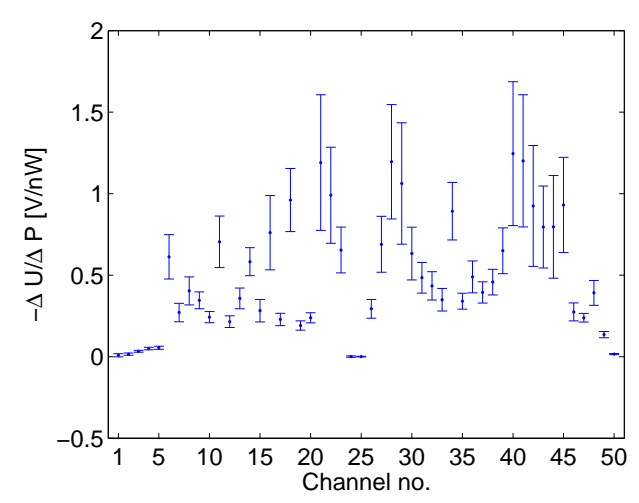

(b)

Figure 6. Channel sensitivity in V/nW for calculated receiver transfer function in figure (a) and tested my multiplier setup in figure (b).

\section{Conclusions}

The receiver uses a heterodyne scheme, i.e. converts RF signals down to IF signals in a downmixing stage. The RF transmission line contains notch-, bandpass- and lowpass filters, a voltagecontrolled variable attenuator, and an isolator. The down-converted IF signal is amplified and divided into three bands using three bandpass filters in the triband box. There are two additional amplifiers in each branch of the triband box, making it three amplifiers in each branch and thereby seven amplifiers in total. The IF filterbanks A, B and C containing 50 bandpass filters will assure passage of signals in the frequency range from 4.5 to $14.5 \mathrm{GHz}$, each channel only at its design frequency band. Square-law detector diodes are used to convert the IF signal down to DC voltage levels which are recorded with 24 bit acquisition cards.

We measured the performance of the individual receiver components which allows us to calculate the predicted receiver response to RF signals at various frequencies in the W-band. This expectation is compared with the response of the receiver as an assembled unit which we measured using a signal generator and a frequency multiplier and two variable attenuators. A scan with varying frequency and power has been performed. The voltages of prediction and measurement differ up to a factor of $2.5(4 \mathrm{~dB})$ for most channels which we find acceptable since the sensitivity is kept at low levels $(<3 \mathrm{~V} / \mathrm{nW})$ for both measurements and expectations. Typical expected CTS signal 
is in the order of $1 \mathrm{eV}$ which corresponds to approximately $15 \mathrm{pW}$ assuming detection bandwidth of $100 \mathrm{MHz}$. Using 24-bit ADC memory cards one can detect power levels of $15 \mathrm{pW}$ with the available receiver sensitivity of $>0.1 \mathrm{~V} / \mathrm{nW}$.

\section{Acknowledgments}

This work, supported by the European Communities under the contract of Association between EURATOM / Risø DTU, was partly carried out within the framework of the European Fusion Development Agreement. The views and opinions expressed herein do not necessarily reflect those of the European Commission.

\section{References}

[1] F. Meo, H. Bindslev, S. B. Korsholm, V. Furtula, F. Leipold, P. K. Michelsen, S. K. Nielsen, M. Salewski, J. Stober, D. Wagner, F. Leuterer, and P. Woskov, "Commissioning activities and first results from the collective Thomson scattering diagnostic on ASDEX Upgrade," Rev. Sci. Instrum., vol. 79, p. 10E501, 2008.

[2] M. Salewski, F. Meo, M. Stejner, O. Asunta, H. Bindslev, V. Furtula, S. B. Korsholm, T. Kurki-Suonio, F. Leipold, F. Leuterer, P. K. Michelsen, D. Moseev, S. K. Nielsen, J. Stober, G. Tardini, D. Wagner, P. Woskov, and ASDEX Upgrade team, "Comparison of fast ion collective Thomson scattering measurements at ASDEX Upgrade with numerical simulations,” Nucl. Fusion, vol. 50, p. 035012, 2010.

[3] F. Meo, M. Stejner, M. Salewski, H. Bindslev, T. Eich, V. Furtula, S. B. Korsholm, F. Leuterer, F. Leipold, P. K. Michelsen, D. Moseev, S. K. Nielsen, B. Reiter, J. Stober, D. Wagner, P. Woskov, and ASDEX Upgrade team, "First results and analysis of collective Thomson scattering (CTS) fast ion distribution measurements on ASDEX Upgrade,” J. Phys.: Conf. Series, vol. 227, p. 012010, 2010.

[4] H. J. Hartfuss, T. Geist, and M. Hirsch, "Heterodyne methods in millimetre wave plasma diagnostics with applications to ECE, interferometry and reflectometry," Plasma Phys. Control. Fusion, vol. 39, no. 11, pp. 1693-1769, 1997.

[5] N. C. Luhmann, H. Bindslev, H. Park, G. Taylor, J. Sanchez, and C. Yu, "Microwave diagnostics," Fusion Sci. Tech., vol. 53, no. 2, pp. 335-396, 2008.

[6] S. B. Korsholm, H. Bindslev, V. Furtula, F. Leipold, F. Meo, P. K. Michelsen, D. Moseev, S. K. Nielsen, M. Salewski, and M. Stejner, "Collective Thomson scattering capabilities to diagnose fusion plasmas," Nucl. Instr. and Methods in Phys. Res., vol. 623, pp. 677-680, 2010.

[7] E. V. Suvorov, V. Erckmann, E. Holzhauer, W. Kasparek, Y. A. Dryagin, S. E. Filchenkov, A. A. Fraiman, T. Geist, M. Kick, L. M. Kukin, A. V. Kostrov, L. V. Lubyako, A. M. Shtanyuk, N. K. Skalyga, and O. B. Smolyakova, "Ion temperature and beam-driven plasma waves from collective scattering of gyrotron radiation in W7-AS," Plasma Phys. Control. Fusion, vol. 37, pp. 1207-1213, 1995.

[8] S. B. Korsholm, M. Stejner, H. Bindslev, V. Furtula, F. Leipold, F. Meo, P. K. Michelsen, D. Moseev, S. K. Nielsen, M. Salewski, M. de Baar, E. Delabie, M. Kantor, and A. Bürger, "Measurements of intrinsic ion Bernstein waves in a tokamak by collective Thomson scattering," Phys. Rev. Lett., vol. 106, p. pp.165004, 2011. 
[9] M. Stejner, S. B. Korsholm, S. K. Nielsen, M. Salewski, H. Bindslev, S. Brezinsek, V. Furtula, F. Leipold, P. K. Michelsen, F. Meo, D. Moseev, A. Bürger, M. Kantor, and M. de Baar, "Measurements of plasma composition in the TEXTOR tokamak by collective Thomson scattering," Plasma Phys. Control. Fusion, vol. 54, no. 1, p. pp.015008, 2012.

[10] H. Bindslev, J. A. Hoekzema, J. Egedal, J. A. Fessey, T. P. Hughes, and J. S. Machuzak, "Fast-ion velocity distributions in JET measured by collective Thomson scattering," Phys. Rev. Lett., vol. 83, pp. 3206-3209, 1999.

[11] E. V. Suvorov, E. Holzhauer, W. Kasparek, L. V. Lubyako, A. B. Burov, Y. A. Dryagin, S. E. Filchenkov, A. A. Fraiman, L. M. Kukin, A. V. Kostrov, D. A. Ryndyk, A. M. Shtanyuk, N. K. Skalyga, O. B. Smolyakova, V. Erckmann, T. Geist, M. Kick, H. Laqua, M. Rust, W7-AS Team, ECRH Team, and NBI Team, "Collective Thomson scattering at W7-AS," Plasma Phys. Control. Fusion, vol. 39, pp. B337-B351, 1997.

[12] U. Tartari, G. Grosso, G. Granucci, L. V. Lubyako, A. G. Shalashov, E. V. Suvorov, F. P. Orsitto, A. Simonetto, S. Nowak, F. Volpe, A. Bruschi, F. Gandini, V. Muzzini, S. Garavaglia, and G. Grossetti, "Critical issues highlighted by collective Thomson scattering below electron cyclotron resonance in FTU," Nucl. Fusion, vol. 46, pp. 928-940, 2006.

[13] U. Tartari, G. Grosso, G. Granucci, F. Gandini, S. Garavaglia, G. Grossetti, A. Simonetto, V. Mellera, V. Muzzini, L. Lubyako, A. Shalashov, F. P. Orsitto, G. Ciccone, and F. Volpe, "Evolution of the millimeter-wave collective Thomson scattering system of the high-field tokamak Frascati Tokamak Upgrade," Rev. Sci. Instrum., vol. 78, p. 043506, 2007.

[14] D. Moseev, F. Meo, S. B. Korsholm, T. Koskela, M. Albergante, O. Asunta, H. Bindslev, A. Buerger, V. Furtula, M. Y. Kantor, F. Leipold, P. K. Michelsen, S. K. Nielsen, M. Salewski, O. Schmitz, M. Stejner, E. Westerhof, and TEXTOR Team, "Comparison of measured and simulated fast ion velocity distributions in the TEXTOR tokamak," Plasma Phys. Control. Fusion, vol. 53, no. 10, p. pp.105004, 2011.

[15] S. K. Nielsen, H. Bindslev, M. Salewski, A. Burger, E. Delabie, V. Furtula, M. Kantor, S. B. Korsholm, F. Leipold, F. Meo, P. K. Michelsen, D. Moseev, J. W. Oosterbeek, M. Stejner, E. Westerhof, P. Woskov, and TEXTOR Team, "Fast-ion redistribution due to sawtooth crash in the TEXTOR tokamak measured by collective Thomson scattering," Plasma Phys. Control. Fusion, vol. 52, p. 092001, 2010.

[16] S. K. Nielsen, M. Salewski, H. Bindslev, A. Burger, V. Furtula, M. Kantor, S. B. Korsholm, H. R. Koslowski, A. Kraemer-Flecken, F. Leipold, F. Meo, P. K. Michelsen, D. Moseev, J. W. Oosterbeek, M. Stejner, E. Westerhof, and TEXTOR Team, "Dynamics of fast ions during sawtooth oscillations in the TEXTOR tokamak measured by collective Thomson scattering," Nucl. Fusion, vol. 51, p. 063014, 2011.

[17] E. Westerhof, S. K. Nielsen, J. W. Oosterbeek, M. Salewski, M. R. De Baar, W. A. Bongers, A. Bürger, B. A. Hennen, S. B. Korsholm, F. Leipold, D. Moseev, M. Stejner, and D. J. Thoen, "Strong scattering of high power millimeter waves in tokamak plasmas with tearing modes," Phys. Rev. Lett., vol. 103, p. 125001, 2009.

[18] S. Kubo, M. Nishiura, K. Tanaka, T. Shimozuma, Y. Yoshimura, H. Igami, H. Takahash, T. Mutoh, N. Tamura, Y. Tatematsu, T. Saito, T. Notake, S. B. Korsholm, F. Meo, S. K. Nielsen, M. Salewski, and M. Stejner, "Collective Thomson scattering of a high power electron cyclotron resonance heating beam in LHD (invited)," Rev. Sci. Instrum., vol. 81, p. 10D535, 2010.

[19] M. Salewski, F. Meo, H. Bindslev, V. Furtula, S. B. Korsholm, B. Lauritzen, F. Leipold, P. K. 
Michelsen, S. K. Nielsen, and E. Nonbøl, "Investigation of first mirror heating for the collective thomson scattering diagnostic in ITER,” Rev. Sci. Instrum., vol. 79, p. 10E729, 2008.

[20] F. Meo, H. Bindslev, S. B. Korsholm, E. L. Tsakadze, S. B. Korsholm, P. Woskov, C. I. Walker, and G. Vayakis, "Design of the collective Thomson scattering diagnostic for international thermonuclear experimental reactor at the $60 \mathrm{GHz}$ frequency range," Rev. Sci. Instrum., vol. 75, pp. 3585-3588, 2004.

[21] F. Leipold, V. Furtula, M. Salewski, H. Bindslev, S. B. Korsholm, F. Meo, P. K. Michelsen, D. Moseev, S. K. Nielsen, and M. Stejner, "Antenna design for fast ion collective Thomson scattering diagnostic for the international thermonuclear experimental reactor," Rev. Sci. Instrum., vol. 80, p. 093501, 2009.

[22] M. Salewski, S. K. Nielsen, H. Bindslev, V. Furtula, N. N. Gorelenkov, S. B. Korsholm, F. Leipold, F. Meo, P. K. Michelsen, D. Moseev, and M. Stejner, "On velocity space interrogation regions of fast-ion collective Thomson scattering at ITER,” Nucl. Fusion, vol. 51, no. 8, p. pp.083014, 2011.

[23] M. Salewski, O. Asunta, L.-G. Eriksson, H. Bindslev, V. Hynönen, S. B. Korsholm, T. Kurki-Suonio, F. Leipold, F. Meo, P. K. Michelsen, S. K. Nielsen, and J. Roenby, "Comparison of collective Thomson scattering signals due to fast ions in ITER scenarios with fusion and auxiliary heating," Plasma Phys. Control. Fusion, vol. 51, no. 3, p. pp.035006, 2009.

[24] M. Salewski, L.-G. Eriksson, H. Bindslev, S. B. Korsholm, F. Leipold, F. Meo, P. K. Michelsen, and S. K. Nielsen, "Impact of ICRH on the measurement of fusion alphas by collective Thomson scattering in ITER,” Nucl. Fusion, vol. 49, p. 025006, 2009.

[25] D. Wagner, G. Grünwald, F. Leuterer, A. Manini, F. Monaco, M. J. Münich, H. Schütz, J. Stober, H. Zohm, T. Franke, M. Thumm, R. Heidinger, G. Gantenbein, A. Meier, W. Kasparek, C. Lechte, A. G. Litvak, G. G. Denisov, A. V. Chirkov, E. M. Tai, L. G. Popov, V. O. Nichiporenko, V. E. Myasnikov, E. A. Solyanova, S. A. Malygin, F. Meo, and P. P. Woskov, "Present status of the new multifrequency ECRH system for ASDEX Upgrade," IEEE Trans. Plasma Sci., vol. 36, pp. 324-331, 2008.

[26] D. Wagner, G. Grünwald, F. Leuterer, A. Manini, F. Monaco, M. Münich, H. Schütz, J. Stober, H. Zohm, T. Franke, M. Thumm, G. Gantenbein, R. Heidinger, A. Meier, W. Kasparek, C. Lechte, A. Litvak, G. G. Denisov, A. V. Chirkov, E. Tai, L. G. Popov, V. Nichiporenko, V. E. Myasnikov, E. A. Solyanova, S. A. Malygin, F. Meo, and P. Woskov, "Status of the new multi-frequency ECRH system for ASDEX Upgrade," Nucl. Fusion, vol. 48, p. 054006, 2008. 